\title{
A tentacle for every occasion: comparing the hunting tentacles and sweeper tentacles, used for territorial competition, in the coral Galaxea fascicularis
}

\author{
Oshra Yosef ${ }^{1}$, Yotam Popovits', Assaf Malik¹,2, Maya Ofek-Lalzer², Tali Mass ${ }^{1 *}$ (D) and Daniel Sher ${ }^{1 *}$
}

\begin{abstract}
Background: Coral reefs are among the most diverse, complex and densely populated marine ecosystems. To survive, morphologically simple and sessile cnidarians have developed mechanisms to catch prey, deter predators and compete with adjacent corals for space, yet the mechanisms underlying these functions are largely unknown. Here, we characterize the histology, toxic activity and gene expression patterns in two different types of tentacles from the scleractinian coral Galaxea fascilcularis - catch tentacles (CTs), used to catch prey and deter predators, and sweeper tentacles (STs), specialized tentacles used for territorial aggression.

Results: STs exhibit more mucocytes and higher expression of mucin genes than CTs, and lack the ectodermal cilia used to deliver food to the mouth and remove debris. STs and CTs also express different sensory rhodopsin-like gprotein coupled receptors, suggesting they may employ different sensory pathways. Each tentacle type has a different complement of stinging cells (nematocytes), and the expression in the two tentacles of genes encoding structural nematocyte proteins suggests the stinging cells develop within the tentacles. CTs have higher neurotoxicity to blowfly larvae and hemolytic activity compared to the STs, consistent with a role in prey capture. In contrast, STs have higher phospholipase A2 activity, which we speculate may have a role in inducing tissue damage during territorial aggression. The expression of genes encoding cytolytic toxins (actinoporins) and phospholipases also differs between the tentacle types.
\end{abstract}

Conclusions: These results show that the same organism utilizes two distinct tentacle types, each equipped with a different venom apparatus and toxin composition, for prey capture and defense and for territorial aggression.

Keywords: Coral, Territorial aggression, Tentacle, Venom, Histology, Transcriptome

\footnotetext{
* Correspondence: tmass@univ.haifa.ac.il; dsher@univ.haifa.ac.il

'Department of Marine Biology, Leon H, Charney School of Marine Sciences, University of Haifa, Haifa, Israel
}

Full list of author information is available at the end of the article

C C The Author(s). 2020 Open Access This article is licensed under a Creative Commons Attribution 4.0 International License, which permits use, sharing, adaptation, distribution and reproduction in any medium or format, as long as you give appropriate credit to the original author(s) and the source, provide a link to the Creative Commons licence, and indicate if changes were made. The images or other third party material in this article are included in the article's Creative Commons licence, unless indicated otherwise in a credit line to the material. If material is not included in the article's Creative Commons licence and your intended use is not permitted by statutory regulation or exceeds the permitted use, you will need to obtain permission directly from the copyright holder. To view a copy of this licence, visit http://creativecommons.org/licenses/by/4.0/ The Creative Commons Public Domain Dedication waiver (http://creativecommons.org/publicdomain/zero/1.0/) applies to the data made available in this article, unless otherwise stated in a credit line to the data. 


\section{Background}

Competition for space among sessile organisms is a common process in the coral reef environment. The constant battle for space, where each organism aims to obtain the optimal access to light, nutrients and food, has resulted in the development of diverse competitive strategies among reef organisms, including the scleractinian corals that form the physical structure of the reef $[16,21]$. As a result, territorial aggression between corals strongly affects the community composition and resulting reef structure [47].

Scleractinian corals employ several methods for territorial aggression (reviewed by [16, 52, 93]), for underwater videos of some of these encounters see [66]. Aggressive encounters can operate over a distance, when mediated by water-borne allelochemicals [4, 30]. At closer range, mucus produced by solitary polyps of the family Fungiidae can cause the degradation of adjacent corals [15], whereas overgrowth of slow-growing corals by faster-growing ones, reducing the access to light and food, can also be considered a form of aggression [16]. Finally, when two corals come into direct physical contact, they may attack each other using their mesenterial filaments (which are usually used for digestion, [51]), "sweeper polyps" [70] or specialized aggression appendages termed sweeper tentacles, which are the focus of the current study.

Sweeper tentacles (STs) develop on the periphery of coral colonies belonging to several different scleractinian families [93], and have been observed also in black corals [36] and gorgonian sea fans [81]. In the scleractinian coral Galaxea fascicularis, STs likely develop from the catch tentacles used for feeding (CTs), since intermediate stages, presenting the features of both catch and sweeper tentacles, can sometimes be observed [42]. The morphogenesis of STs occurs over several days to weeks following the initiation of contact with competitors (or damage caused by competition), although they sometimes develop without any clear cue $[17,54]$. At the end of their development, STs can be up to 30 times longer than CTs (Fig. 1b), and have not been observed to participate in feeding. The contact of a ST with the tissue of a target organism results in tissue damage (lesions) which can also be associated with a cessation of skeleton growth along the contact region between the two competing colonies (Fig. 1a). In at least some organisms, STs are temporary structures, regressing after destroying the opponent's tissue [17].

While the presence of STs in different corals and their ecological role in territorial aggression have been extensively studied (primarily during the 1980's), little is known about the mechanism of aggression at the molecular and biochemical levels. Cnidarians are known to produce complex and highly effective toxins that are used to catch prey and defend themselves against predators (recently reviewed by $[48,80]$ ). These toxic cocktails are typically injected into prey or predators through specialized stinging cells called nematocytes [8, 88], although some toxins are released from epithelial cells or even deposited into oocytes [19, 64, 83]. Most cnidarians, including corals, produce several types of nematocytes, and the nematocytes found in the STs are different from those in the CTs. For example, in Galaxea fascicularis, the acrospheres (the tentacle tips, which contain numerous nematocytes) of STs consist of approximately 50\% Large Microbasic b-Mastigophores (L-MbM, which penetrate into target tissues and presumably inject toxins) and almost $40 \%$ spirocysts [42], which do not penetrate into the target tissue and have primarily an adhesive role. In contrast, CTs consist of $80 \%$ spirocysts and the remainder are mainly Microbasic p-Mastigophores (MpM), another type of penetrating nematocyte [42]. Thus, while it is likely that the nematocysts and the toxins they produce have an important role in aggression, the specific mechanisms underlying the aggression at the molecular level are currently unknown.

To obtain insights into the mechanism of territorial aggression, we performed in-depth comparison of the CTs and STs of the Indo-Pacific scleractinian coral Galaxea fascicularis at the histological, biochemical and molecular levels. Galaxea fascicularis is a massive (boulder-shaped) coral that is known to be highly aggressive, both towards other species and towards geneticallydifferent clades or morphotypes from the same species $[1,34]$. G. fasciularis develop ST in response to the presence of a potential competitor [42], and may also use their mesenterial filaments for aggression [28]. The STs of G. fasciularis have been studied from an organismalbehavioral point of view (e.g. the effect of genetic similarity and of flow [34, 41], and the dynamics of their development have been characterized [42]. We therefore employed a comparative transcriptomics approach, and we discuss specific genes and pathways differentially expressed between the two tentacle types in relation to detailed observations of the histology of the two tentacle types, their nematocyst complements and their toxicity (neurotoxic, hemolytic and phospholipase A2 activities).

\section{Results}

Differences in the tissue structure between catch and sweeper tentacles

The Catch Tentacles (CTs) and Sweeper Tentacles (STs) of Galaxea fascicularis have very different macroscopic morphologies, with the ST being up to 30 times longer than CTs (Fig. 1b). To identify the tissue structures potentially underlying these morphological differences, we produced histological sections of the two tentacle types using two different stains - the classical Hematoxylin- 


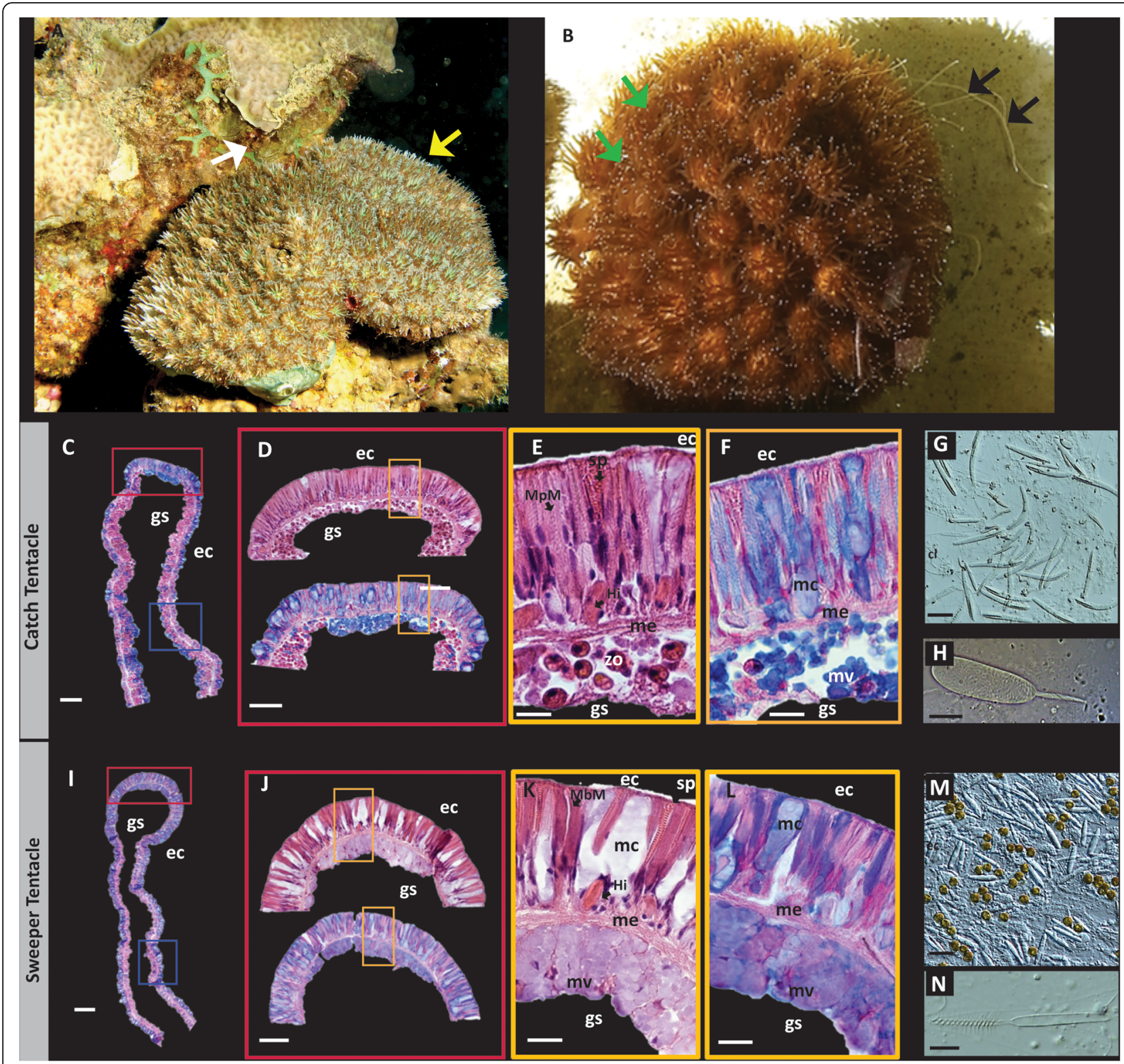

Fig. 1 Overview of G. fascicularis and its two tentacle types. a The result of aggressive behavior between Galaxea fascicularis and Pavona sp. The yellow arrow shows the Galaxea, the white arrow shows the dead area between the two corals. Photo taken in Eilat by Tali Mass. b Catch tentacles $(C T$, green arrow) and extended sweeper tentacles (ST, black arrow) of G. fascicularis. c and i Overall histology of Alcian Blue-stained CT (c) and ST (i). Red boxes show the approximate location of high-magnification micrographs in this figure, blue squares show approximate location of micrographs in Fig. 2. $\mathbf{d}$-f Histological sections of the tip of the CT, stained with H\&E (upper section in $\mathbf{d}$ and panel $\mathbf{e}$ ) and with Alcian Blue (lower section in $\mathbf{d}$ and panel $\mathbf{f}$ ). e and $\mathbf{f}$ are magnifications of the orange square in (d). Note the tightly-packed large nematocytes in the ectoderm (ec, sp - spirocysts, MpM Microbasic p Mastigophores) and the abundance of symbiotic algae (zo) in the endoderm (en). $\mathbf{g}, \mathbf{h}$ Main types of nematocytes of the acrosphere (Microbasic p Mastigophores, MpMs, which have a smooth shaft, unlike the barbed shaft of the MbMs of the sweeper tentacles). i-I Histological sections of the tip of the ST, stained with H\&E (upper section in $\mathbf{j}$ and panel $\mathbf{k}$ ) and with Alcian Blue (lower section in $\mathbf{j}$ and panel $\mathbf{I}$ ). $\mathbf{k}$ and $\mathbf{I}$ are magnifications of the yellow square in (j). Note the mucocytes in the ectoderm between the large, elongated nematocytes, and the lack of symbionts in the endoderm. Mucocytes (mc), mucus vesicles (mv) and nematocysts are stained in blue, the latter perhaps due to the presence of poly-gammaglutamate (an acidic polyanion) in the capsule matrix of the nematocysts. Hi-Holotrichous isorhiza nematocytes. $\mathbf{m}, \mathbf{n}$ Main types of nematocytes of the acrosphere of the ST (Microbasic b Mastogophores, MbMs). Scale bars are $100 \mu \mathrm{m}$ for (c and $\mathbf{i}), 50 \mu \mathrm{m}$ for (d and $\mathbf{j}), 200 \mu \mathrm{m}$ for (e, f, $\mathbf{k}$ and $\mathbf{~ I ) , ~} 25 \mu \mathrm{m}$ for $(\mathbf{g}, \mathbf{m})$ and $10 \mu \mathrm{m}$ for $(\mathbf{h}, \mathbf{n})$ 

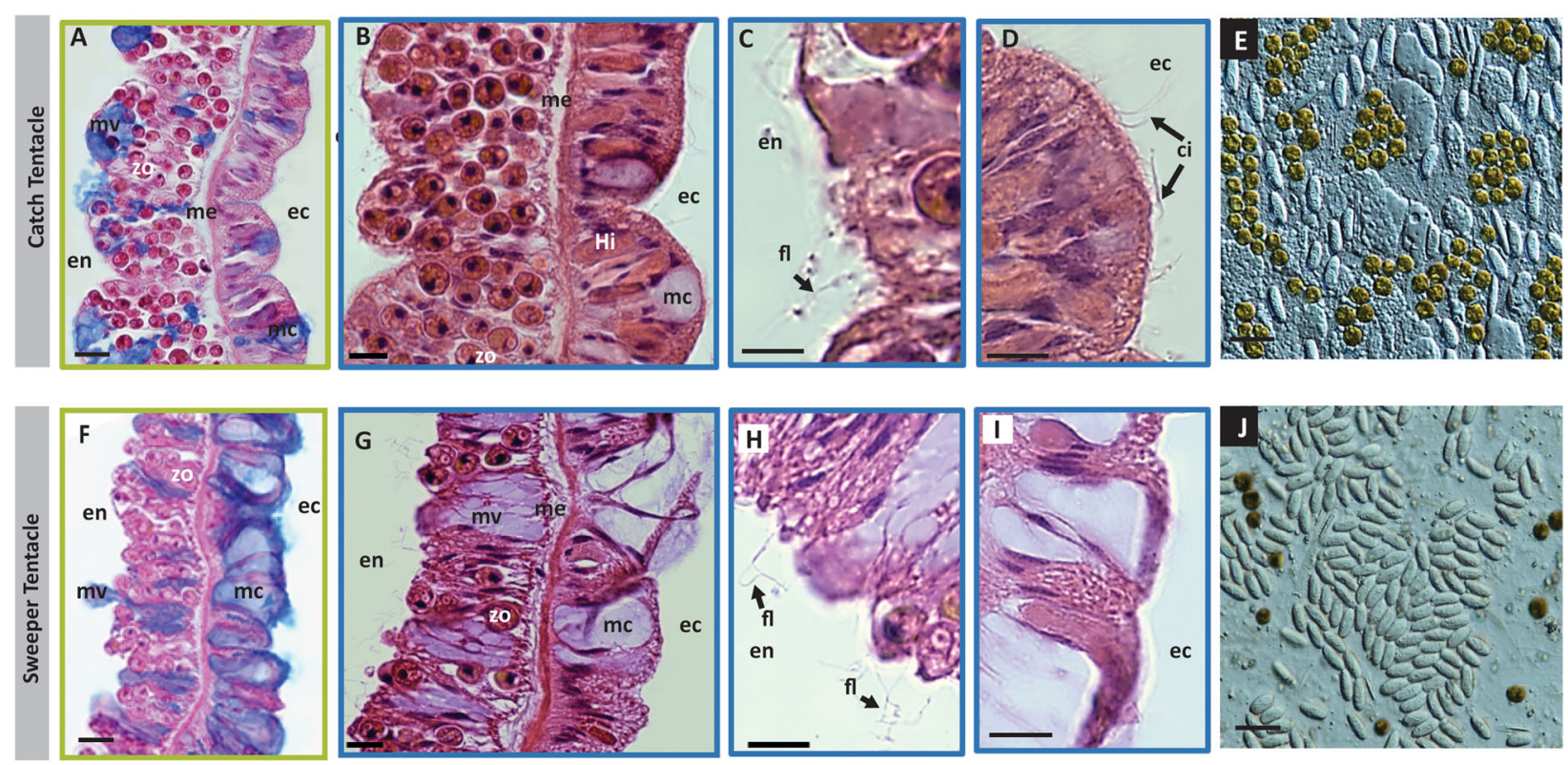

Fig. 2 Comparison of the base of the two tentacle types - abundant secretory mucocytes and lack of cilia in the ecotoderm of ST compared to CT. Catch (a-d) and sweeper (e-h) tentacles sections are shown, respectively, stained with Alcian blue $(\mathbf{a}, \mathbf{f})$ and H\&E (b-d, $\mathbf{g}$-i). The endodermal layer (en) is wider than the ectodermal layer (ec), especially in the CT, with higher number of zooxanthellae symbionts (zo) in the CTs in

comparison to the STs (compare $\mathbf{a}, \mathbf{b}$ with $\mathbf{f}, \mathbf{g}$ ). Flagella (fl) can be observed on the endodermal layer of both tentacle types (c, $\mathbf{h}$ ), facing the gastrovascular lumen. In contrast, ectodermal cilia (ci) are present only in catch tentacles (d) e, $\mathbf{j}$ Squash assays of the base area of catch and sweeper tentacles respectively, composed mainly from of holotrichous isorhiza nematocysts. Note here too the higher density of zooxanthellae in the CTs. Scale bars: a, b, f, g $20 \mu \mathrm{m} ; \mathbf{c}, \mathbf{d}, \mathbf{h}, \mathbf{i} 10 \mu \mathrm{m} ; \mathbf{e}, \mathbf{j} 25 \mu \mathrm{m}$

Eosin (H\&E) stain and Alcian Blue, a cationic dye which stains primarily acidic polysaccharides. As shown in Figs. 1 and 2, major histological differences are observed between the tentacles. Starting at ectoderm of the tip of the tentacle (the acrosphere), the CT can be characterized by a dense layer of nematocytes, including mostly spirocysts and Microbasic p-Mastigophores (MpMs) (Fig. 1c-h). In contrast, while many nematocytes were observed also at the tip of the STs, these were less dense than in the $\mathrm{CT}$, and there were many more mucus secreting cells compared with the CT (Fig. 1j-l). Unlike the CTs, the nematocysts of the ST were mainly Microbasic b-mastigophpores (MbMs, Fig. 1m, n), including a type not observed at all in the STs (very large MbMs). The different types of nematocytes are consistent with the observations of Hidaka [42]. The endoderm of the two tentacles types was also different, with the CTs characterized by many symbiotic algae residing within the endodermal cells (Figs. 1e and 2) and the STs comprising many mucus vesicles, making it difficult to distinguish individual cells (Fig. 11).

Similar to the tips of the tentacles, at the base of the tentacles there was also a much higher density of mucocytes in the STs compared to the CTs (compare Fig. 2a, $\mathrm{b}$ to $\mathrm{f}, \mathrm{g}$ ). The endoderm layer of the CTs was wider than that of the STs, and had a higher density of zooxanthellae (Fig. 2). The nematocytes at the base of the CTs and
STs were similar, comprising mainly holotrichous isorhiza (HI, Fig. 2e, j).

A major difference between the CT and ST, observed in Hematoxylin-Eosin stained sections of the two tentacle types, was the lack of ectodermal cilia on the surface of STs (Fig. 2i, compared to D). However, flagella were observed at the endodermal layer of both tentacles type (Fig. 2c, h). Ectodermal cilia are involved in the ciliary-mucoid feeding and cleansing processes, by helping to capture particulate food and transporting it towards the coral's mouth. They also may help clean the coral surface from sediment entrapped in the mucus [13].

\section{Overview of the transcriptome assembly and differential gene expression patterns}

To obtain an overview of the molecular differences between CTs and STs, we sequenced, assembled de-novo and annotated transcriptomes from the two tentacle types of four different specimens of G. fascicularis. We also sequenced whole-body transcriptomes from three specimens, with the aim of obtaining a comprehensive transcriptome database. The final database comprised a total of 28,588 putative genes, somewhat more than predicted from a recently published draft genome $(22,418$, [94]). Clear differences were observed between the transcriptome profiles of the two tentacle types, and between them and the whole-body samples (Fig. 3a, 

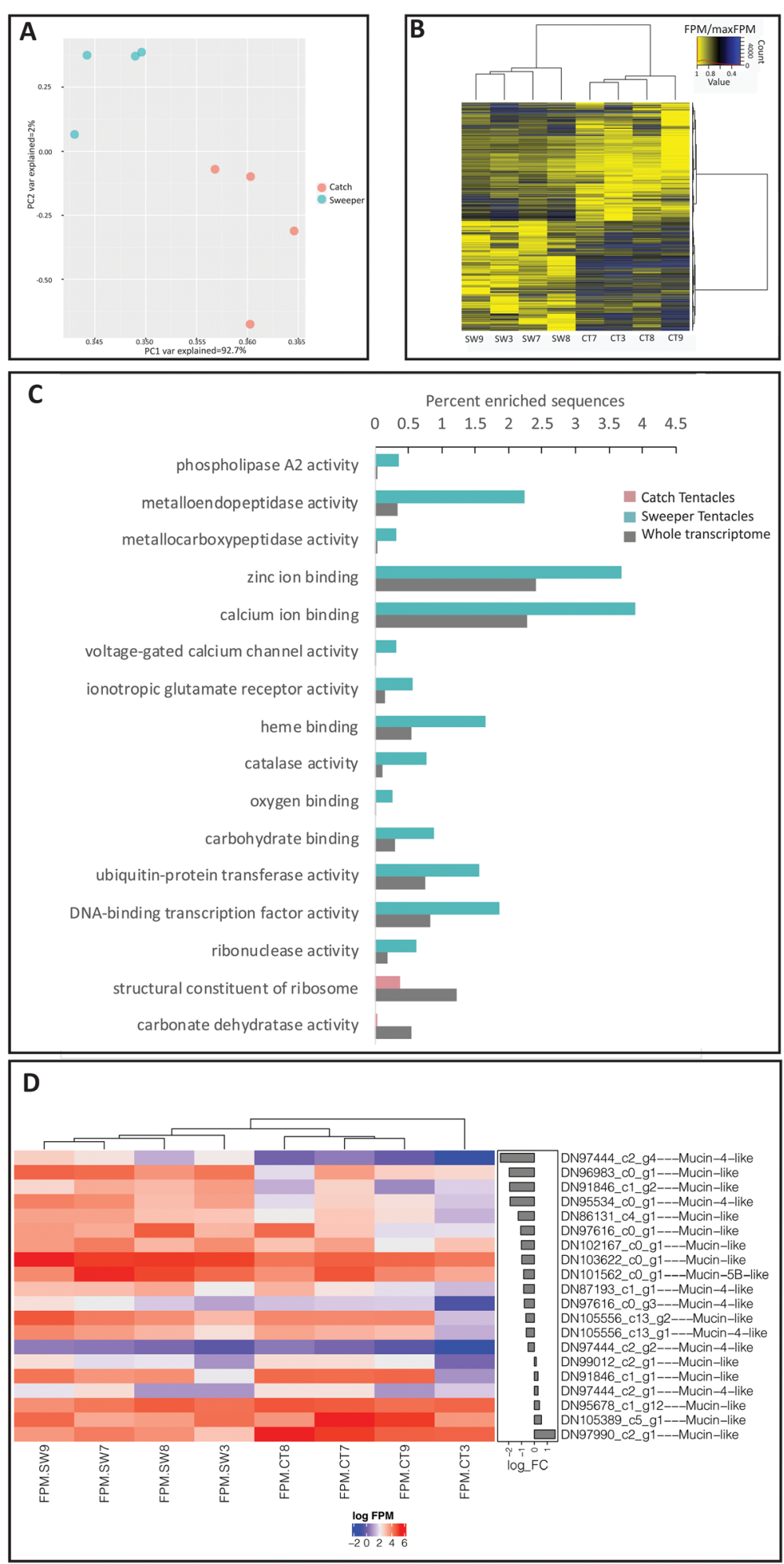

Fig. 3 (See legend on next page.) 
(See figure on previous page.)

Fig. 3 Overview of the gene expression in the two tentacle types. a Principal Component Analysis plot for sweeper tentacles (blue) and catch tentacles (red). Each point represents tentacles collected from a single colony of G. facsicularies. b A heatmap showing the expression patterns of differentially expressed genes between the ST and CT ( $\log _{10}$ Fragments Per Million or FPM). Note the variability between the four biological replicates from paired tentacles and three biological replicates from the body. c Gene Ontology terms enriched in the sweeper and catch tentacles. The reference represents the abundance of these terms in the full transcriptome. $\mathbf{d}$ Differences in the expression of putative mucinencoding genes between the CT and the ST

Supplementary Figure 2). Despite the clear clustering of the samples based on tentacle type, significant variability was observed between the same tentacle types from different colonies (Fig. 3b, an interactive version of this figure is available as Supplementary Data File 1). Such inter-colony variability is in agreement with previous studies [82]. Pairwise comparisons between the two tentacles type revealed that 1585 genes were more highly expressed in the STs compared to 1165 genes more highly expressed the CTs (adjusted $p$-value $<0.05$ after Benjamini and Hochberg correction, Supplementary Excel Table). Enrichment analysis showed that 14 Gene Ontology (GO) terms were enriched among the genes more abundantly expressed in the STs, whereas only two were enriched in the CT (Fig. 3c). Two terms enriched in the STs, phospholipases and metalloproteases, are suggestive of functions involved in venom toxicity ([14, 55], see below). Similarly, the enrichment of GO terms in the STs related to voltage gates calcium channel and ionotropic glutamate receptor activities suggest differences in the pathways of cellular signal transduction and synaptic excitatory transmission between the two tentacle types. Other enriched pathways in the STs include carbohydrate binding, heme and oxygen binding, catalase and several other molecular functions.

The broad-scale observations of changes in gene expression led us to examine the expression patterns of specific genes that might be related to differences in the tissue structure of the two tentacle types. Since we observed differences in the distribution of mucocytes, we first asked whether there are differences in the expression of genes encoding mucins (Supplementary Table 1). Indeed, eight genes encoding mucins were more abundantly expressed in the STs, compared with only one such gene in the CTs (Fig. 3d). In contrast, despite the presence of ectodermal cilia in the CTs but not the STs, no clear differences were observed between the CTs and STs in the expression of genes involved in the synthesis of cilia or flagella (Supplementary Excel file). We also asked whether we could identify differences in the expression of genes encoding nematocyst structural components, which might be related to the different nematocytes found in each tentacle type. We identified transcripts encoding the nematocyst-specific genes nematogalectin and NOWA (Nematocyst Outer Wall Antigen), both of which were more abundantly expressed in the STs (Supplementary Table 2). However, we didn't identify differences in the sequence of the nematogalectin and NOWA transcripts between the two tentacle types. Such a difference would have suggested that the different nematocysts found in the tentacles (Figs. 1 and 2) each harbor a different version of these proteins, as previously shown for different nematocyte types in Hydra, but evidently this is not the case in $G$. fasciularis $[26,45]$.

\section{Sensory G-protein coupled receptor genes are differentially expressed between the CTs and STs}

Catch and sweeper tentacles both need to respond to environmental cues, and these cues are likely different catch tentacles need to rapidly respond to chemical and physical stimuli from motile prey whereas sweeper tentacles exhibit "searching" behavior [54], and potentially can respond more slowly as their targets are sessile. Once they have identified their targets, both tentacle types discharge nematocytes. As described above, GO terms related to calcium cellular signaling and ionotropic glutamate receptor activity were enriched in genes more abundantly expressed in the ST (Fig. 3c), suggesting differences in the sensory or neuronal circuitry between the tentacle types. Recently, G-protein-coupled receptors (GPCRs) have been implicated in environmental sensing in another marine invertebrate, the Crownof-thorns sea-star Acanthaster plancii [39, 92]. Motivated by this study, we identified 52 genes encoding rhodopsin-like GPCRs in the full transcriptome data from G. fascicularis (Supplementary Table 3). Of these genes, 16 and 12 genes found to be more abundantly expressed in the ST and CT respectively (Supplementary Excel file). The GPCR genes more abundantly expressed in the CT included two histamine $\mathrm{H} 2$-like receptor genes (out of a total of 3), multiple genes encoding Substance-K receptors and QRFP-like peptide receptors (Supplementary Excel file). In the ST, multiple genes encoding non-visual photoreceptor (NVP) genes such as Melanopsin and Melatonin receptors were more abundantly expressed, as were several other genes encoding receptors for neuropeptides (e.g. RYamide and tachykinin). A gene encoding a putative Allostatin receptor, which in Hydra was shown to have myoregulatory activity effecting the shape and length of the tentacles [2], was also more abundantly expressed in the ST. 
The CTs and STs differ in the expression of toxinencoding genes and in three types of tissue toxicity

The primary ecological roles of the catch and sweeper tentacles are to affect target organisms, presumably using nematocyst-derived venom or other toxins. The venom of cnidarians has been studied extensively, and is comprised primarily of proteins and polypeptides, including neurotoxins, pore-forming hemolysins, phospholipase A2 (PLA2) toxins and a wide variety of enzymes such as proteases (recently reviewed by $[48,80]$ ). Therefore, to begin elucidating the molecular mechanism underlying the different ecological functions of the venoms, we searched for known cnidarian toxins in the transcriptomes of the CTs and STs. In total, we identified 23 genes encoding putative toxins that belong to four different classes of toxins: hemolytic toxins, phospholipase enzymes toxins, metalloprotease and Kunitz type toxins (Fig. 4a) Supplementary Table 4. We also measured the paralytic, hemolytic and phospholipase A2 activity of tissue extracts from both tentacle types, in order to seek potential relationships between the expressed genes and actual toxic activities.

We identified five genes encoding putative hemolytic toxins, belonging to two distinct families: Actinoporins and CrTX-A like toxins (Fig. 4a, Supplementary Excel file). A total of four distinct actinoporin genes were identified, with two of the isoforms more abundantly expressed in the STs and one in the CTs (Fig. 4a). A single gene encoded a putative hemolytic toxin from a different family, similar to CrTX-A from the Box Jellyfish Carybdea rastonii which is potently hemolytic and lethal by injection mice and crayfish [67]. The CrTX-A like

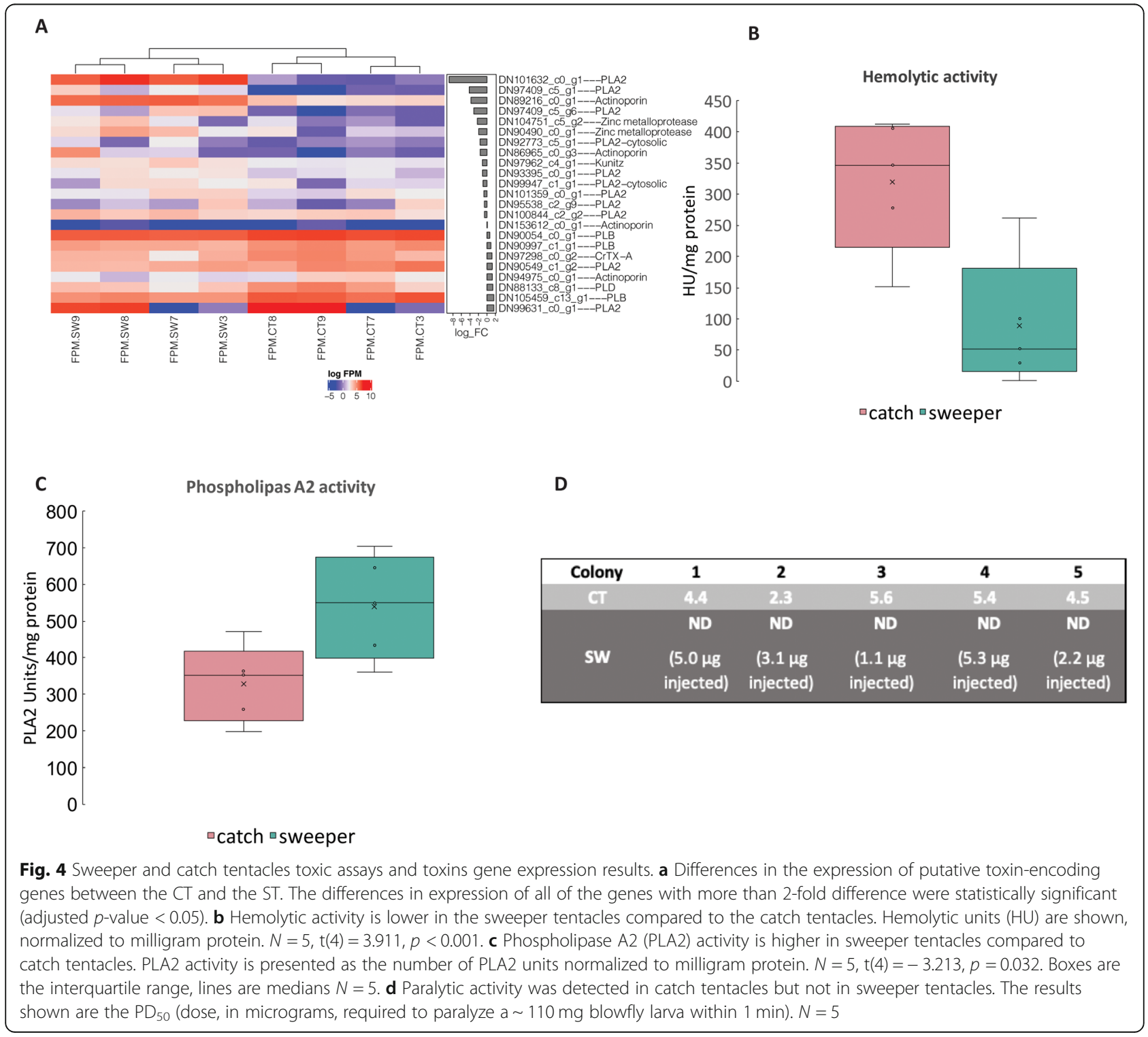


toxin was expressed 3-fold more in the CTs compared with the ST (Fig. 4a). In agreement with the expression of genes encoding putative hemolysins, both tentacle types exhibited hemolytic activity, with the CT extracts being approximately 3 -fold more hemolytic than the STs (Fig. 4b).

We also identified eight different genes encoding putative Phospholipase A2 (PLA2) toxins, which had the highest levels of expression and also the highest fold change between tentacle types of all putative toxinencoding genes (e.g. up to $\sim 900$-fold higher expression level of one gene in the STs compared with the CTs, Fig. 4a). Four of the putative PLA2-encoding genes were more abundantly expressed in the CTs and four in the STs (Fig. 4a). In this case too, PLA2 activity was identified in the extracts of both tentacles, but in contrast to the hemolytic activity was significantly stronger in the STs (Fig. 4c). Genes encoding metalloproteases were also identified, and were more abundantly expressed in the STs (Fig. 4a).

Paralyzing prey organisms is the basic role of cnidarian venom used to catch prey, and, as expected, the CTs exhibited paralytic activity (Fig. 4d). No paralysis was observed in any of the larvae injected with the water extract of the STs, even at the highest injected doses (Fig. 4d, marked as "ND"-not detected). In addition, all larvae injected with the extract from the CTs died within several hours of injection, whereas all larvae injected with the extracts from the STs survived after $24 \mathrm{~h}$. We note that due to the limited amount of ST biomass available, in some pairs (e.g. from colonies 3 and 5), the injected dose from the STs was below the dose required to paralyze $50 \%$ of the injected larvae $\left(\mathrm{PD}_{50}\right)$ of the catch tentacles, thus precluding a direct statistical test of the difference in paralytic activity. Nevertheless, these results suggest that even if paralytic toxins are found in the STs, their concentration and/or activity is much lower than those of the catch tentacles. We were unable to identify transcripts encoding any of the known peptide toxins targeting $\mathrm{Na}^{+}$or $\mathrm{K}^{+}$channels [48], with the exception of a putative Kunitz-type toxin. Such proteins can potentially inhibit $\mathrm{K}^{+}$channels but can also act as a protease inhibitors [74]. However, the expression of the putative Kunitz type toxin was slightly higher in the STs, suggesting that it is not the molecule responsible for the paralytic activity.

\section{Discussion}

Over millions of years, scleractinian corals have evolved methods to aggressively compete for territory on the often-crowded coral reef. These aggressive interactions are one of the main factors leading to the complex physical structure of coral reefs, which provides the substrate and shelter for some of the worlds' most biodiverse ecosystems [16, 21]. While a variety of aggressive mechanisms have been described, molecular mechanisms of underpinning these interactions, and how they are related to the morphology and histology of the interacting organisms, are mostly unknown. In the following discussion, we use the transcriptomic results combined with observations based on histology and toxicity bioassays to begin elucidating the mechanisms of interaction in Galaxea fascicularis, one of the more well-studied models of coral aggression [28, 34, 41, 42].

\section{Histological adaptations for prey capture vs territorial aggression}

Several major histological differences were observed between the CTs and the STs, with perhaps the most apparent being the lack of ectodermal cilia and the higher density of mucocytes in the ectoderm of the STs (including at the base of the tentacles, Fig. 2). The coral mucus is essential for many aspects of coral biology, including heterotrophic feeding, protection from parasites, pathogens and environmental stresses, sediment cleansing and structural support [13]. In addition, in cnidarians, mucus may play both modulatory and effector roles in territorial aggression. Mucus may play a role in allorecognition by cnidarians, for example by promoting the discharge of nematocytes against other species while inhibiting the discharge when encountering the same species or other tentacles from the same organism [27, 38]. It may also have a direct alleloptahic role, causing damage to target organisms [15], and may contain bioactive molecules or toxins [86]. It is noteworthy that some of the most aggressive corals, including Galaxea fascicularis, are known to produce copious amounts of mucus [13]. Major differences were observed in the expression of genes encoding mucins (Fig. 3d), with many mucinencoding genes more abundantly expressed in the STs. Mucins are a family of large glycoproteins $(0.5-20 \mathrm{MDa})$ formed from a central protein core with heavily glycosylated side-chains, and are known to be key component in most gel-like secretions [5]. Mucins can be membranebound or secreted (gel-forming), and together, both types of mucin generate the characteristic mucus layer $[43,89]$. The eight genes more abundantly expressed in the ST were all homologs of MUC1, a membrane-bound mucin which is anchored directly to the cell membrane and is involved (in other organisms) in surface protection, cell-cell interactions, adhesion and signal transduction [23]. The increase in mucocyte density and MUC1 gene expression in STs compared to CTs suggest that mucus may have a prominent role in the aggression mechanism, potentially as a "carrier" for toxins that are not derived from the stinging cells $[6,9,19,64]$.

In the CTs of corals, one of the roles of the mucus produced by the ectodermal cells is to produce a flow 
along the tentacles, bringing food particles towards the mount [13]. This process is powered by the movement of ectodermal cilia, and is called a ciliary-mucoid feeding. The lack of the cilia on the ectodermal surface of the STs supports the notion that these tentacles do not participate in feeding, and suggest that qualitatively different mucus might be involved in aggression compared to ciliary-mucoid feeding. In contrast, the endodermal cells of both tentacle types exhibited flagella, which are involved in circulating the gastrovascular fluid through the tentacles both as an internal transport system and as the driving force for the tentacles' hydrostatic skeleton [35]. No clear differences were observed between the CTs and STs in the expression of genes involved in the synthesis of cilia and flagella (Supplementary Table 5, Supplementary excel Table). However, two histamine H2-like receptor genes were found more highly expressed in the CTs, and one such gene was more abundantly expressed in the body, with no such genes more abundantly expressed in the STs (Supplementary Excel Table). Histamine $\mathrm{H} 2$ receptors have been shown to play part in the mucociliary transport mechanisms in ascidians and mollusks, by controlling ciliary beat frequency [18]. The lower expression of these genes in the ST may be due to the lack of cilia and of the mucociliary transport mechanism in these tentacles.

\section{Nematocyte development and regulation in the CT and the ST}

Nematocytes are the main venom delivery system in cnidarians, and previous studies have shown that the nematocytes of the CTs and STs differ [42]. Specifically, the acrosphere of the CTs contain mostly spirocysts and Microbasic p-Mastigophores (MpMs), whereas STs contain many Microbasic b-mastigophpores (MbMs) and somewhat fewer spirocysts [42]. These differences were observed also between the CTs and STs in our animals, which were collected $\sim 8700 \mathrm{Km}$ apart from those studied by Hidaka in 1984, and which may belong to different genotypes [50]. The three nematocyst types, MbM, $\mathrm{MpM}$ and $\mathrm{HI}$ (with the latter found primarily at the base of the tentacles), are all penetrating nematocytes, and thus may be used to deliver toxins into the target organism. The spirocysts, in contrast, do not penetrate the target, but rather entangle it. The higher abundance of spirocysts in the CTs may be related to the need to ensnare mobile prey organisms in order to feed on them, a requirement not shared by the STs.

In Hydra, nematocytes develop from their precursor cells in the body column, and during this period many of the proteins comprising the nematocyst structure are expressed, including nematogalectins and NOWA [45]. The mature nematocytesthen migrate up the body column and into the tentacles, where they are mounted into the ectodermanl batteries. At this stage, expression of structural nematocyst genes is no longer observed [45]. In contrast, little is known about the patterns of development of nematocysts in other cnidarians, although a NOWA-like gene is expressed in the tentacles of the primary polyp of Nematostella [87], and nematogalectins are expressed in the tentacle bulb of the jellyfish Clytia hemisphaerica where nematogenesis has been shown to occur $[22,45]$. Our results showing the expression of nematogalectins and NOWA in the CTs and the ST, and the higher expression level in the STs compared to the CTs, suggest that the development of the nematocysts in G. facsicularies, including the change in nematocyte composition as the STs develop from CTs [42], occurs in the tentacles. We did not identify transcripts encoding Cnidoin or Spinalin, either in our transcriptome or in the recently published draft genome [94]. This is in accordance with the suggestion that spinalin, which forms the spines decorating the tubules of some Hydra nematocysts, is restricted to Hydra [63], and highlights how little we know about the molecular underpinnings of the rich array of cnidarian nematocytes.

The discharge of nematocytes in cnidarians is a highly regulated process. While nematocytes may discharge when stimulated individually, they are innervated and regulated by the cnidarian nerve net [88]. Given that the nematocytes of the CTs need to discharge in response to mobile prey, whereas those in the STs need to respond to closely-related sessile targets, it is likely that the processes regulating their discharge are different. Little is known about the discharge mechanism of nematocytes involved in aggression, although an electrical "action potential" was measured in the acrorhagi of sea anemones in response to the identification of a non-self target [60]. Intriguingly, we identified two GO terms, voltage gates calcium and ionoptropic glutamate activity, as enriched in the STs compared with the CTs. Signaling by glutamate regulates nematocyte discharge in other cnidarians [49]. Similarly, in Hydra, light inhibits nematocyte discharge through opsin-mediated phototransduction [71], and we identified non-visual photoreceptor (NVP) GPCR genes such as Melanopsin and Melatonin as more abundantly expressed in the STs. To what extent ionotropic glutamate transmission and photoreceptors are involved in mediating nematocyte discharge, or whether their role lies in mediating other behavioral aspects of the STs activity such as the search activity, remains to be determined.

One organism, two tentacles, two functions, two venoms The primary function of the catch and sweeper tentacles are to affect target organisms, presumably using nematocyst-derived venom or other, non-nematocystic, toxins. For the CTs, the targets are the coral's prey or 
predators. In the case of prey, the venom needs to cause rapid paralysis, enabling the sessile predator to catch and eat mobile prey [12]. In the case of predator deterrence, pain production rather than paralysis might be a better ecological end-point (e.g. [40, 46, 73]). In contrast, the target of the ST are territorial competitors, and therefore the venom likely does not need to induce paralysis but rather to cause tissue damage [6]. Consistent with this view, we observed both qualitative and quantitative differences in the toxicity profile between the CTs and the STs - only the CTss contain a paralytic (presumably neurotoxic) activity, whereas both tentacle types contain hemolytic and PLA2 activities, but the CT are more hemolytic and the STs have more PLA2 activities (Fig. 4). This suggests that while the neurotoxic activity is dispensable for territorial aggression, the hemolytic and PLA2 activities may be relevant for both aggression and prey/predator encounter.

At the molecular level, different toxic proteins may be responsible for the observed hemolytic and PLA2 activities in each tentacle type. In the case of hemolysins, two out of four actinoporin transcripts were more abundantly expressed in the STs, whereas one actinoporin and a transcript encoding a CrTX-A like toxin were more abundantly expressed in the CTs. Actinoporins are widely distributed in cnidarians, including in corals [9], and in some cases have been shown to originate from the nematocysts $[7,44,76]$. In addition, different nematocytes may each contain a different actinoporin [44]. In contrast, in the aggressive organs of the sea anemone Actinia equina, actinoporins are found in the tissue extract but not in the nematocyte venom [6], as shown for other toxins in Nematostella vectensis [19, 64]. These observations suggest the potential for significant functional differences between different actinoporins. Importantly, pore-forming toxins, to which both the actinoporin and CrTX-A like toxins belong, can cause cell lysis but may also have neurotoxic-paralytic activities $[79,95]$. We therefore speculate that the actinoporin and CrTX-A like toxins found in the CT may have stronger lethal activities, whereas those more abundantly expressed in the ST may induce tissue damage and potentially inflammation, potentially through the induction of cell death mechanisms in the target tissue $[68,85]$. Importantly, while actinoporins have been intensively studied from evolutionary, biochemical and structural perspectives (e.g. as models of how water-soluble proteins interact with cell membranes, $[3,62]$ ), little is known about their actual effect on the target organisms (prey, predators or competitors) or the ecological role of this protein family in cnidarians.

Similar to the hemolysins, different PLA2 genes were more abundantly expressed in each type of tentacle, again suggesting a potential functional differentiation between different toxins from the same family. We speculate that the PLA2 toxins more abundantly expressed in the CTs may have a neurotoxic effect (e.g. $[58,78])$, whereas the isoforms more abundantly expressed in the ST may cause tissue damage, potentially through the activation of the Lyso-PAF and PAF inflammation pathways in the target coral $[33,75]$.

Interestingly, PLA2 toxins, as well as metalloproteases and kunitz-type serine protease toxins, were all more abundantly expressed in the aggressive organs (acrorhagi) of the sea anemone Anthopleura elegantissima compared to non-aggressive polyps [61]. We also observed several metalloproteases and a putative Kunitztype toxin that were more abundantly expressed in the ST (Fig. 4a). Metalloproteases are important venom components of most venomous animals including cnidarians, where they can cause tissue degradation [31, 72, 91]. Metalloproteases, mostly belonging to the Astacinlike family, have previously been detected in the soluble nematocyst content of jellyfish, Hydra, sea anemones and corals [32, 48, 57, 65, 76]. We speculate that these three toxin types - PLA2s, metalloproteases and Kunitztype protease inhibitors - may form a "functional triad", playing an important role in the tissue-degrading effect of venom in general, and the venom involved in territorial aggression in corals in particular.

\section{Conclusions}

The coral reef is a highly competitive place, where the morphologically simple and sessile corals need to be able to "fight" in parallel on different fronts - catching prey, defending themselves against predators and competing in territorial aggressive encounters with other corals. We propose a conceptual model describing some physiological and molecular features of the two different tentacle types of Galaxea fascicularis, each of which has evolved to address a different ecological challenge. Our results suggest that the CTs are adapted to catch prey using paralytic toxins and hemolysins, likely injected through the MpM nematocytes, with spirocytes helping to entangle the prey. The prey is then transferred to the mouth using cilia combined with a mobile mucus layer, and the ciliary beating is controlled by the Histamine $\mathrm{H} 2$ system. The ST, in contrast, actively "search" for their long-distance targets, with the tentacle length and movement (and potentially the nematocyte discharge) controlled by the opsin and allostatin sensory systems. Once the target organism is identified, the ST deliver primarily enzymatic venom through the two different MbM nematocyte types, as well as (potentially) as part of the extensive non-nematocytic mucus secretion. We speculate that the ST mucus may have a higher relative composition of membrane-bound glycoproteins (such as mucins), thus being less of a "mobile" or flowing mucus 
cover. This mucus might also play a role in the recognition of self vs non-self tissue. This conceptual model is based on histological observations, functional toxicity assays and analyses of differential gene expression, and provides several hypotheses that can be tested using experimental tools currently available for non-model corals such as Galaxea fascicularis.

The venom of one organism - the coral - needs to produce three different functional outcomes - paralysis, pain and tissue degradation. The need for venom to fulfill different roles is not unique to corals - scorpions, cone snails and assassin bugs, for example, each produce multiple venom cocktails that nevertheless are injected through the same venom apparatus $[25,46,90]$. In the case of the coral, the morphological distinction between the CT and ST enable each to produce a unique chemical armament. However, it is also possible that within each tentacle type there may be more than one type of venom. For example, in Hydra, different nematocytes are discharged in response to prey and to predators [29, 84]. Additionally, many cnidarians also employ toxins that are not delivered through the stinging cells $[19,64,83]$. It remains to be tested whether, within each tentacle type, different effector molecules or toxins are delivered through different cell types. If so, this "division of labor" might enable a complex chemical armament to be delivered in a target- and time-specific manner.

Our results also leave many questions open. For example, the genes more abundantly expressed in the ST are enriched with the GO terms "oxygen binding" and "heme", yet the relationship between these molecular functions and the biology of the STs is still unclear. Genes encoding RNAase, transcription factor binding and ubiquitin-protein transferase activities are also enriched in the ST, suggesting a constant dynamic remodeling of these tentacles, a process that has yet to be studied in detail. In contrast, despite the clear differences in cilia and flagella between the two tentacle types, no differences were observed in the expression of their structural genes. It is possible that post-translational regulation plays a role in the regulation of the development and function of these organelles. Finally, approximately $34 \%$ of the genes identified in the transcriptome could not be functionally annotated, including $4 \%$ of the genes differentially expressed between the CT and the ST. This highlights the richness of molecular functions still to be discovered that allow these corals to survive and thrive on the coral reef.

\section{Methods}

\section{Specimen collection and histology}

Tentacle samples were obtained from the Underwater Observatory Park, Eilat, Israel. Paired catch and sweeper tentacles were collected from G. fascicularis colonies exhibiting the same morphotype (brown with a green oral disc), all located in the same large aquarium. The water in the aquarium is drawn directly from the Red Sea at water depth of $42 \mathrm{~m}$, and natural ambient light is used. Thus, the aquarium reflects to some extent the natural diel and seasonal changes in the Red Sea reef ecocystem. Sweeper and catch tentacles for RNA extraction were collected from 4 different G. fascicularis colonies ( $n=4$ for each tentacle type) and from 5 different G. fascicularis colonies for the bioassays analysis $(n=5$ for each tentacle type). Tentacles were cut from the colonies by a SCUBA diver, placed in $50 \mathrm{ml}$ Falcon tubes and immediately brought up to the surface. Excess water was discarded, for RNA extraction TRIzol ${ }^{\circ}$ Reagent was added to the samples and the samples were snap-frozen in liquid nitrogen and were maintained at $-80{ }^{\circ} \mathrm{C}$ till further processing. For histological and microscopic analyses, tentacles were anesthetized in $0.3 \mathrm{M}$ magnesium chloride for $10 \mathrm{~min}$, and either observed fresh (for "squash assays") or fixed in $2 \%$ forma-glutaraldehyde solution for $72 \mathrm{~h}$ at $4{ }^{\circ} \mathrm{C}$ and transferred to $70 \%$ ethanol at $4{ }^{\circ} \mathrm{C}$ till histological processing was performed. Embedding into paraffin blocks, sectioning into $4-\mu \mathrm{m}$ sections and histological staining were all performed using the Ventana BenchMark fully automated slide stainer system at the Histology Service Center at Carmel Hospital, Haifa Israel. Two staining techniques were used: H\&E (hematoxylin and eosin) for cell visualization and Alcian blue for identifying acid mucopolysaccharides and acidic mucins. Microscopic observations were performed using a Nikon Eclipse Ti microscope, with nematocysts identified as previously described [69].

\section{RNA extraction, transcriptome sequencing and quality control}

The tentacles for RNA extraction were collected at 17:00 on March 20th, 2017. Samples from the polyp body ( $n=$ 3) were also collected for this analysis, in order to allow the assembly of a comprehensive transcriptome database that includes additional polyp parts such as the body column, the mesenteries and the basal disc. Total RNA was extracted after thawing the tissues and electric homogenization using TRIzol $^{\circ}$ followed by purification with the Zymo Quick-RNA ${ }^{\mathrm{Tm}}$ MiniPrep kit. Libraries were prepared using the Genomics in house protocol at the Weizmann Institute of Sciences Genome Center for mRNA-seq. Briefly, the polyA fraction (mRNA) was enriched from $500 \mathrm{ng}$ of total RNA followed by fragmentation and the generation of double-stranded cDNA. Then, end repair, A base addition, adapter ligation and PCR amplification steps were performed. Libraries were evaluated by Qubit (Thermo fisher scientific) and TapeStation (Agilent). Sequencing libraries were constructed with unique barcodes for each sample to allow 
multiplexing. Around 18-24 million 125-bp Paired-End reads were sequenced per sample on an Illumina HiSeq 2500 High Output instrument (version 4). Paired End $(\mathrm{PE})$ reads were adapter-trimmed using cutadapt 1.15 (https://cutadapt.readthedocs.io), in two rounds (--times $=2$ parameter). Average low-quality (Phred < 25) regions were removed with Trimmomatic 3.0 using a $10 \mathrm{bp}$ sliding window [11]. Reads where less than $50 \mathrm{bp}$ were left after trimming were excluded. The resulting trimmed reads were inspected using FastQC (www.bioinformatics.babraham.ac.uk). Reads mapping to human genes, NCBI UniVec databases, ribosomal RNA databases [10], and Symbiodiniaceae genes (the genomebased predicted transcripts of Symbiodinium microadriaticum CCMP2467 -NCBI accession GCA 001939145.1, Symbiodinium minutum from https://marinegenomics.oist.jp, Symbiodinium kawagutii http:// symbs.reefgenomics.org/download and the transcriptomes of Symbiodinium aenigmaticum, Symbiodinium minutum, Symbiodinium pseudominutum, Symbiodinium psygmophilum downloaded from http://www.reefgenomics.org), were filtered out, using FastQ Screen v0.4.4 (www.bioinformatics.babraham.ac.uk). Since FastQ Screen uses Bowtie2 mapper [53], which is only designed to align highly similar sequences, not all Symbiodiniaceae species could be excluded at this step. Therefore, additional detection methods were used to exclude symbionts after assembly (see below).

\section{Transcriptome assembly and annotations}

The genome of Galaxea fascicularis has recently been published [94]. We mapped the reads onto the published genome using STAR, with $36-64 \%$ of the reads uniquely aligning. The fraction of mapped reads was higher in the sweeper tentacles compared to the catch tentacles (52$64 \%$ compared with 36-48\%). In contrast, about twofold more reads mapped to the Symbiodiniaceae genomes in the catch compared to the sweeper tentacles, in agreement with the histological observations presented in Figs. 1 and 2. Nevertheless, we chose to perform de-novo transcriptome assembly rather than use the published genome as a reference, in order to avoid mapping biases due to potential genomic diversity within this species, as shown previously for another coral, Stylophora pistillata [50]. The reads after quality control were assembled using Trinity 2.4 [37] with default settings, except for the addition of Slurm cluster management setting (Trinity arguments: grid_exec, grid_conf). For assembly diagnostics, PE reads were mapped back to the assembly using Bowtie2 default PE settings. 78-85\% of all the PE reads were concordantly aligned to the same contig, which are typical results for such de-novo assembly using Trinity. The N10, and N50, of the largest isoforms per Trinity genes is $4490 \mathrm{bp}$ and $1222 \mathrm{bp}$ respectively (e.g., N10 indicates that $10 \%$ of the assembled bases are found in contigs with at least N10 value of bp length). Trinity produces contigs (equivalent to transcripts), which can be clustered into Trinity-genes. For Trinity genes with open reading frames (ORFs) 2100aa long (github.com/TransDecoder/TransDecoder), the largest ORF was compared to the NCBI nr database version 2018-12 using BLASTX (v2.2.28). In addition, we used the tools Trinotate 3.0.1 (https://trinotate. github.io) and Blast2GO (https://www.blast2go.com) for functional annotations.

\section{Transcript quantitation and differential expression analysis}

PE reads abundance, at the Trinity gene level, was estimated with RSEM v1.2.30 [56]. From all Trinity genes quantified by RSEM, only genes with unambiguous metazoan-origin were selected (excluding NCBI nr 2018-12 proteins mapped to Symbiodiniaceae or other non-metazoa genes, as well as un-annotated genes). Species origin was estimated by first finding the best NCBI NR database hits for the longest ORFs using blastp, and then detecting species origin based on the NCBI gi id to taxonomy database (ftp://ftp.ncbi.nih.gov/pub/taxonomy). Overall, for the different samples, $77-82 \%$ of all quality-filtered reads were mapped with RSEM to 360 , 065 Trinity contigs (most of these genes possibly represent non-coding transcripts). After selecting only annotations matched exclusively to Metazoa, $24-37 \%$ of all mapped reads remained (4.2-8.7 million reads remained per sample, median 7.7 million, namely median of $32 \%$ of all mapped reads), in 28,588 Trinity genes, considering the catch and sweeper samples. Additional 6.5-11 million reads were mapped to Alveolata and Bacteria (median of $44 \%$ of mapped reads). It should also be noted that Trinity assembler typically produces hundreds of thousands of contigs, with a large proportion of non-coding transcripts. Differential expression analysis (DE) was conducted using Bioconductor DESeq2 ( $R$ v3.4.2), using only the samples of the two tentacle types, considering two factors in the DESeq2 GLM models: tissue identity (catch, sweeper) and specimen (paired colonies number $3,7,8,9$ ) [59]. The whole-body samples were not included in the analysis of differential expression, as they were collected from additional colonies, for the purpose of assembling a comprehensive transcriptome. We further verified the general horizontal symmetry of the resulting MA plot in DEseq2 in catch vs. sweeper samples (Supplementary Figure 1), and also tested for comparable normalized count frequency distribution between samples. NMDS (non-metric multidimensional scaling), and PCA (Principal component analysis) ordinations by groups were conducted in $R$ using the Vegan package [24], and R prcomp function, 
respectively. Gene Ontology annotation and enrichment analyses were performed using BLAST2GO [20]. The results were then narrowed down using the BLAST2GO function "reduce to more specific", which removes generic functions if their more specific child term is also significant. For the identification of toxin and GPCR genes, a reciprocal best-BLAST-hit (RBBH, [76]) approach was utilized, with an additional BLAST e-value cutoff of $10^{-5}$. The protein sequences of toxins from [76], and of G-protein-coupled receptors (GPCRs) and genes involved in cilia/flagella from [39], were searched against the Trinity assembly using BLASTX. The BLAST hits, as well as additional sequences identified as GPCRs from the BLAST2GO annotation of the transcriptome, were compared by reciprocal BLAST to the Swiss-Prot database release 2018_02 to verify their annotation.

\section{Bioassays}

The tentacles were thawed, $1 \mathrm{ml}$ of PBS (Phosphate Buffered Saline) was added, homogenization was performed using an electric homogenizer for $10 \mathrm{~s}$, and the homogenate was centrifuged for $5 \mathrm{~min}$ at $5000 \mathrm{rpm}$. The supernatant (crude water extract) was used for all bioassays. Paralytic activity was assessed by injection to Sarcophaga faculata blowfly larvae [96], average weight $110 \pm 20 \mathrm{mg}$ ) and a positive result was scored when full immobilization of the larva was observed within $60 \mathrm{~s} .5-10 \mu \mathrm{l}$ was injected at each time, with PBS serving as a negative control. $\mathrm{PD}_{50}$ (paralytic dose - defined as the amount of protein needed to paralyze 50\% of the tested animals) was determined for every sample and was calculated according to the estimation method of Reed and Muench [77], with 3-5 larvae injected per concentration tested. Tests for hemolytic activity (the ability to lyse human red blood cells) were performed as described in [9], using $\mathrm{O}$ Rh positive human blood Type obtained from the Yoseftal Hospital Blood Bank. One hemolytic unit (HU50) was defined as the amount of protein sample required to cause 50\% hemolysis, with phosphate buffered saline serving as a negative control ( $0 \%$ hemolysis) and doubledistilled water as the $100 \%$ hemolysis point. Phospholipase A2 (PLA2) activity was measured using the EnzChek ${ }^{\circ}$ Assay Kit, using honey-bee venom PLA2 as a positive control and to produce a standard curve. The kits limit of detection was 0.05 Units $/ \mathrm{ml}$, with one PLA2 unit defined as the amount of protein needed to hydrolyze of $1 \mu$ mole of $\mathrm{L}$ aphosphatidylcholine to L-a-lysophosphatidylcholine and a fatty acid per minute at $\mathrm{pH} 8.0$ at $37^{\circ} \mathrm{C}$. Protein concentration was measured using the $\mathrm{BCA}$ protein kit (Pierce $\mathrm{BCA}$ ), with Bovine Serum Albumin (BSA) used to produce a standard curve ranging from 2 to $0.2 \mathrm{mg} / \mathrm{ml}$ protein. Statistical tests for the bioassays were performed using paired samples $t$-test using IBM SPSS Statistics software. All data were normally distributed based on the Shapiro-Wilk normality test, and significance at a 0.05 level was used for all tests. Since no paralytic activity was detected in sweeper tentacles, results could not be statistically analyzed but differences were clear between tentacle types.

\section{Supplementary information}

Supplementary information accompanies this paper at https://doi.org/10. 1186/s12864-020-06952-W.

Additional file 1. Supplementary figures 1 and 2, Supplementary Tables $1-5$.

Additional file 2. Supplementary interactive version of figure $3 B$ (html file).

Additional file 3. Supplementary Excel file with transcripts assembled by Trinity, their expression levels and annotations.

\section{Acknowledgements}

We thank the Dive Team of the Underwater Observatory in Eilat for assistance with sample collection and to Dr. Salam Mazarab from Carmel Medical Center for her help with preparing our histology samples. We thank the Crown Genomics institute of the Nancy and Stephen Grand Israel National Center for Personalized Medicine, Weizmann Institute of Science, for sequencing.

\section{Authors' contributions}

OY, TM and DS designed research, OY, YP, AM, MOL, TM and DS performed research and analyzed data, OY, TM and DS wrote the paper with contributions from all authors. All authors have read and approved the manuscript.

\section{Funding}

This study was supported by grants $1239 / 13$ and 312/15 from the Israel Science Foundation (to DS and TM, respectively) and by the associated grant number 2236/16 from the Israeli National Center for Personalized Medicine (to DS). Computations presented in this work were performed on the Hive computer cluster at the University of Haifa, which is partly funded by ISF grant $2155 / 15$. The funding bodies played no role in the design of the study and collection, analysis, and interpretation of data and in writing the manuscript.

\section{Availability of data and materials}

The RNA-Seq raw data (fastq files), and Trinity assembly, were deposited in the NCBI Sequence Read Archive (SRA) and the NCBI Transcriptome Shotgun Assembly (TSA) databases (https://www.ncbi.nlm.nih.gov/) under BioProject ID: PRJNA640524.

\section{Ethics approval and consent to participate}

Tentacle samples were obtained from the Underwater Observatory Park, Eilat, Israel under a permit \# 2016/41493 from the Israeli Natural Parks Authority.

Consent for publication

Not applicable.

\section{Competing interests}

The authors declare that they have no competing interests.

\section{Author details}

'Department of Marine Biology, Leon H, Charney School of Marine Sciences, University of Haifa, Haifa, Israel. ${ }^{2}$ Bioinformatics Support Unit, University of Haifa, Haifa, Israel.

Received: 8 April 2020 Accepted: 27 July 2020

Published online: 08 August 2020

\section{References}

1. Abelson A, Loya Y. Interspecific aggression among stony corals in Eilat, red sea: a hierarchy of aggression ability and related parameters. Bull Mar Sci. 1999;65(3):851-60. 
2. Alzugaray ME, Hernández-Martínez S, Ronderos JR. Somatostatin signaling system as an ancestral mechanism: Myoregulatory activity of an AllatostatinC peptide in Hydra. Peptides. 2016;82:67-75. https://doi.org/10.1016/j. peptides.2016.05.011.

3. Anderluh $G$, Macek P. Dissecting the actinoporin pore-forming mechanism. Structure (Camb). 2003;11(11):1312-3.

4. Atrigenio M, Ali OP, Conaco C. Influence of the Blue coral Heliopora coerulea on scleractinian coral larval recruitment. J Mar Biol. 2017;2017:5. https://doi. org/10.1155/2017/6015143

5. Bansil R, Turner BS. Mucin structure, aggregation, physiological functions and biomedical applications. Curr Opin Colloid Interface Sci. 2006;11(2):16470. https://doi.org/10.1016/j.cocis.2005.11.001.

6. Bartosz G, Finkelshtein A, Przygodzki T, Bsor T, Nesher N, Sher D, Zlotkin E. A pharmacological solution for a conspecific conflict: ROS-mediated territorial aggression in sea anemones. Toxicon. 2008;51(6):1038-50.

7. Basulto A, Perez VM, Noa Y, Varela C, Otero AJ, Pico MC. Immunohistochemical targeting of sea anemone cytolysins on tentacles, mesenteric filaments and isolated nematocysts of Stichodactyla helianthus. J Exp Zool A Comp Exp Biol. 2006;305A(3):253-8.

8. Beckmann A, Ozbek S. The nematocyst: a molecular map of the cnidarian stinging organelle. Int J Dev Biol. 2012;56(6-8):577-82. https://doi.org/10. 1387/ijdb.113472ab.

9. Ben-Ari H, Paz M, Sher D. The chemical armament of reef-building corals: inter- and intra-specific variation and the identification of an unusual actinoporin in Stylophora pistilata. Sci Rep. 2018;8(1):251. https://doi.org/10. 1038/s41598-017-18355-1.

10. Bengtsson-Palme J, Hartmann M, Eriksson KM, Pal C, Thorell K, Larsson DGJ, Nilsson RH. metaxa2: improved identification and taxonomic classification of small and large subunit rRNA in metagenomic data. Mol Ecol Resour. 2015; 15(6):1403-14. https://doi.org/10.1111/1755-0998.12399.

11. Bolger AM, Lohse M, Usadel B. Trimmomatic: a flexible trimmer for Illumina sequence data. Bioinformatics. 2014;30(15):2114-20. https://doi.org/10.1093/ bioinformatics/btu170.

12. Brodie ED III. Toxins and venoms. Curr Biol. 2009;19(20):R931-5. https://doi. org/10.1016/j.cub.2009.08.011.

13. Brown BE, Bythell JC. Perspectives on mucus secretion in reef corals. Mar Ecol Prog Ser. 2005;296:291-309.

14. Casewell NR. On the ancestral recruitment of metalloproteinases into the venom of snakes. Toxicon. 2012;60(4):449-54. https://doi.org/10.1016/j. toxicon.2012.02.006

15. Chadwick NE. Competition and locomotion in a free-living fungiid coral. J Exp Mar Biol Ecol. 1988;123(3):189-200. https://doi.org/10.1016/00220981(88)90041-X.

16. Chadwick NE, Morrow KM. Competition among sessile organisms on coral reefs. In: Dubinsky Z, Stambler N, editors. Coral reefs: an ecosystem in transition. Dordrecht: Springer Netherlands; 2011. p. 347-71.

17. Chornesky EA. Induced development of sweeper tentacles on the reef coral Agaricia agaricites: a response to direct competition. Biol Bull. 1983;165(3): 569-81. https://doi.org/10.2307/1541466.

18. Cima F, Franchi N. Histamine stimulates ciliary beat frequency via the $\mathrm{H} 2$ receptor in the Protochordate Botryllus schlosseri. J Exp Zool B Mol Dev Evol. 2016;326(3):176-92. https://doi.org/10.1002/jez.b.22675.

19. Columbus-Shenkar YY, Sachkova MY, Macrander J, Fridrich A, Modepalli V, Reitzel AM, Moran Y. Dynamics of venom composition across a complex life cycle. eLife. 2018;7:e35014. https://doi.org/10.7554/eLife.35014

20. Conesa A, Gotz S, Garcia-Gomez JM, Terol J, Talon M, Robles M. Blast2GO: a universal tool for annotation, visualization and analysis in functional genomics research. Bioinformatics. 2005;21(18):3674-6. https://doi.org/10 1093/bioinformatics/bti610

21. Connell JH, Hughes TP, Wallace CC, Tanner JE, Harms KE, Kerr AM. A Longterm study of competition and diversity and diversity of corals. Ecol Monogr. 2004;74(2):179-210. https://doi.org/10.1890/02-4043.

22. Denker $E$, Manuel $M$, Leclère L, Le Guyader $H$, Rabet N. Ordered progression of nematogenesis from stem cells through differentiation stages in the tentacle bulb of Clytia hemisphaerica (Hydrozoa, Cnidaria). Dev Biol. 2008; 315(1):99-113. https://doi.org/10.1016/j.ydbio.2007.12.023.

23. Dhar P, McAuley J. The role of the cell surface mucin MUC1 as a barrier to infection and regulator of inflammation. Front Cell Infect Microbiol. 2019;9: 117. https://doi.org/10.3389/fcimb.2019.00117.

24. Dixon P. VEGAN, a package of $R$ functions for community ecology. J Veg Sci. 2003;14(6):927-30. https://doi.org/10.1111/j.1654-1103.2003.tb02228.x.
25. Dutertre S, Jin A-H, Vetter I, Hamilton B, Sunagar K, Lavergne V, Lewis RJ. Evolution of separate predation- and defence-evoked venoms in carnivorous cone snails. Nat Commun. 2014;5(1):3521. https://doi.org/10. 1038/ncomms4521.

26. Engel U, Oezbek S, Engel R, Petri B, Lottspeich F, Holstein TW. Nowa, a novel protein with minicollagen Cys-rich domains, is involved in nematocyst formation in Hydra. J Cell Sci. 2002; 115(20):3923-34. https://doi.org/10.1242/jcs.00084.

27. Ertman SC, Davenport D. Tentacular nematocyte discharge and "selfrecognition" in Anthopleura elegantissima Brandt. Biol Bull. 1981;161(3):36670. https://doi.org/10.2307/1540941.

28. Evensen NR, Edmunds PJ. Effect of elevated $\mathrm{pCO}_{2}$ on competition between the scleractinian corals Galaxea fascicularis and Acropora hyacinthus. J Exp Mar Biol Ecol. 2018;500:12-7. https://doi.org/10.1016/j.jembe.2017.12.002.

29. Ewer RF. On the functions and mode of action of the nematocysts of Hydra. Proc Zool Soc Lond. 1947;117:365-76.

30. Fearon RJ, Cameron AM. Preliminary evidence supporting the ability of hermatypic corals to affect adversely larvae and early settlement stages of hard coral competitors. J Chem Ecol. 1997;23(7):1769-80. https://doi.org/10. 1023/B:JOEC.0000006450.55638.b2.

31. Feitosa L, Gremski W, Veiga SS, Elias MCQB, Graner E, Mangili OC, Brentani RR. Detection and characterization of metalloproteinases with gelatinolytic, fibronectinolytic and fibrinogenolytic activities in Brown spider (Loxosceles intermedia) venom. Toxicon. 1998;36(7):1039-51. https://doi.org/10.1016/ S0041-0101(97)00083-4.

32. Gacesa R, Chung R, Dunn SR, Weston AJ, Jaimes-Becerra A, Marques AC, Long PF. Gene duplications are extensive and contribute significantly to the toxic proteome of nematocysts isolated from Acropora digitifera (Cnidaria: Anthozoa: Scleractinia). BMC Genomics. 2015;16(1):774. https://doi.org/10. 1186/s12864-015-1976-4.

33. Galtier d'Auriac I, Quinn RA, Maughan H, Nothias L-F, Little M, Kapono CA, Hartmann AC. Before platelets: the production of platelet-activating factor during growth and stress in a basal marine organism. Proc R Soc B Biol Sci. 2018;285(1884):20181307. https://doi.org/10.1098/rspb.2018.1307.

34. Genin A, Karp L, Miroz A. Effects of flow on competitive superiority in scleractinian corals. Limnol Oceanogr. 1994;39(4):913-24.

35. Gladfelter EH. Circulation of fluids in the gastrovascular system of the reef coral Acropora cervicornis. Biol Bull. 1983;165(3):619-36. https://doi.org/10. 2307/1541469.

36. Goldberg WM, Grange KR, Taylor GT, Zuniga AL. The structure of sweeper tentacles in the black coral Antipathes fiordensis. Biol Bull. 1990;179(1):96104. https://doi.org/10.2307/1541743.

37. Grabherr MG, Haas BJ, Yassour M, Levin JZ, Thompson DA, Amit I, Regev A. Full-length transcriptome assembly from RNA-Seq data without a reference genome. Nat Biotechnol. 2011;29(7):644-52. https://doi.org/10.1038/nbt. $1883 \mathrm{nbt} .1883$

38. Gundlach KA, Watson GM. Self/non-self recognition affects Cnida discharge and tentacle contraction in the sea Anemone Haliplanella luciae. Biol Bull. 2018;235(2):83-90. https://doi.org/10.1086/699564.

39. Hall MR, Kocot KM, Baughman KW, Fernandez-Valverde SL, Gauthier MEA, Hatleberg WL, Degnan BM. The crown-of-thorns starfish genome as a guide for biocontrol of this coral reef pest. Nature. 2017;544(7649):231-4. https:// doi.org/10.1038/nature22033.

40. Harris RJ, Jenner RA. Evolutionary ecology of fish venom: adaptations and consequences of evolving a venom system. Toxins. 2019;11(2):60. https:// doi.org/10.3390/toxins 11020060 .

41. Hidaka M. Nematocyst discharge, histoincompatibility, and the formation of sweeper tentacles in the coral Galaxea fascicularis. Biol Bull. 1985;168(3):3508. https://doi.org/10.2307/1541517.

42. Hidaka M, Yamazato K. Intraspecific interactions in a scleractinian coral, Galaxea fascicularis: induced formation of sweeper tentacles. Coral Reefs. 1984;3(2):77-85. https://doi.org/10.1007/bf00263757.

43. Hollingsworth MA, Swanson BJ. Mucins in cancer: protection and control of the cell surface. Nat Rev Cancer. 2004;4(1):45-60. https://doi.org/10.1038/nrc1251.

44. Hwang JS, Ohyanagi H, Hayakawa S, Osato N, Nishimiya-Fujisawa C, Ikeo K, Gojobori T. The evolutionary emergence of cell type-specific genes inferred from the gene expression analysis of Hydra. Proc Natl Acad Sci U S A. 2007; 104(37):14735-40. https://doi.org/10.1073/pnas.0703331104.

45. Hwang JS, Takaku Y, Momose T, Adamczyk P, Özbek S, Ikeo K, Gojobori T. Nematogalectin, a nematocyst protein with GlyXY and galectin domains, demonstrates nematocyte-specific alternative splicing in Hydra. Proc Natl Acad Sci. 2010;107(43):18539-44. https://doi.org/10.1073/pnas.1003256107. 
46. Inceoglu B, Lango J, Jing J, Chen L, Doymaz F, Pessah IN, Hammock BD. One scorpion, two venoms: prevenom of Parabuthus transvaalicus acts as an alternative type of venom with distinct mechanism of action. Proc Natl Acad Sci U S A. 2003;100(3):922-7.

47. Jackson JB, Buss L. Alleopathy and spatial competition among coral reef invertebrates. Proc Natl Acad Sci U S A. 1975;72(12):5160-3. https://doi.org/ 10.1073/pnas.72.12.5160

48. Jouiaei M, Sunagar K, Federman Gross A, Scheib H, Alewood PF, Moran Y, Fry $B G$. Evolution of an ancient venom: recognition of a novel family of cnidarian toxins and the common evolutionary origin of sodium and potassium neurotoxins in sea Anemone. Mol Biol Evol. 2015;32(6):1598-610. https://doi.org/10.1093/molbev/msv050.

49. Kass-Simon G, Scappaticci AA. Glutamatergic and GABAnergic control in the tentacle effector systems of Hydra vulgaris. In: Fautin DG, Westfall JA, Cartwrigh P, Daly M, Wyttenbach CR (eds) Coelenterate Biology 2003. Developments in Hydrobiology. Dordrecht; 2004;178. https://doi.org/10. 1007/978-1-4020-2762-8 8

50. Keshavmurthy S, Yang S-Y, Alamaru A, Chuang Y-Y, Pichon M, Obura D, Chen CA. DNA barcoding reveals the coral "laboratory-rat", Stylophora pistillata encompasses multiple identities. Sci Rep. 2013;3:1520. https://doi. org/10.1038/srep01520 https://www.nature.com/articles/srep0152 0\#supplementary-information.

51. Lang J. Interspecific aggression by scleractinian corals. 2 . Why the race is not only to the swift. Bull Mar Sci. 1973;23:260-179.

52. Lang J, Chornesky EA. Competition between scleratinian reef corals - a review of mechanisms and effects. In: Dubinsky Z (ed) Ecosystems of the world, V. 25. Coral reefs: Elsevier; 199:209-52.

53. Langmead B, Salzberg SL. Fast gapped-read alignment with Bowtie 2. Nat Methods. 2012;9(4):357-9. https://doi.org/10.1038/nmeth.1923.

54. Lapid ED, Chadwick NE. Long-term effects of competition on coral growth and sweeper tentacle development. Mar Ecol Prog Ser. 2006;313:115-23.

55. Lee H, Jung E-S, Kang C, Yoon WD, Kim J-S, Kim E. Scyphozoan jellyfish venom metalloproteinases and their role in the cytotoxicity. Toxicon. 2011; 58(3):277-84. https://doi.org/10.1016/j.toxicon.2011.06.007.

56. Li B, Dewey CN. RSEM: accurate transcript quantification from RNA-Seq data with or without a reference genome. BMC Bioinformatics. 2011;12(1):323. https://doi.org/10.1186/1471-2105-12-323.

57. Li R, Yu H, Xue W, Yue Y, Liu S, Xing R, Li P. Jellyfish venomics and venom gland transcriptomics analysis of Stomolophus meleagris to reveal the toxins associated with sting. J Proteome. 2014;106:17-29. https://doi.org/10. 1016/j.jprot.2014.04.011.

58. Lotan A, Fishman L, Zlotkin E. Toxin compartmentation and delivery in the cnidaria: the nematocyst's tubule as a ultiheaded poisonous arrow. J Exp Zool. 1996;275:444-51.

59. Love Ml, Huber W, Anders S. Moderated estimation of fold change and dispersion for RNA-seq data with DESeq2. Genome Biol. 2014;15(12):550. https://doi.org/10.1186/s13059-014-0550-8

60. Lubbock $R$, Shelton GAB. Electrical activity following cellular recognition of self and non-self in a sea anemone. Nature. 1981;289(1):59.

61. Macrander J, Brugler MR, Daly M. A RNA-seq approach to identify putative toxins from acrorhagi in aggressive and non-aggressive Anthopleura elegantissima polyps. BMC Genomics. 2015;16(1):221. https://doi.org/10.1186/s12864-015-1417-4.

62. Macrander J, Daly M. Evolution of the cytolytic pore-forming proteins (Actinoporins) in sea anemones. Toxins. 2016;8(12):368.

63. Milde S, Hemmrich G, Anton-Erxleben F, Khalturin K, Wittlieb J, Bosch TCG. Characterization of taxonomically restricted genes in a phylum-restricted cell type. Genome Biol. 2009;10(1). https://doi.org/10.1186/Gb-2009-10-1-R8.

64. Moran Y, Genikhovich G, Gordon D, Wienkoop S, Zenkert C, Özbek S, Gurevitz M. Neurotoxin localization to ectodermal gland cells uncovers an alternative mechanism of venom delivery in sea anemones. Proc R Soc B Biol Sci. 2011. https://doi.org/10.1098/rspb.2011.1731.

65. Moran Y, Praher D, Schlesinger A, Ayalon A, Tal Y, Technau U. Analysis of soluble protein contents from the nematocysts of a model sea anemone sheds light on venom evolution. Mar Biotechnol (NY). 2013;15(3):329-39. https://doi.org/10.1007/s10126-012-9491-y.

66. Mullen AD, Treibitz T, Roberts PLD, Kelly ELA, Horwitz R, Smith JE, Jaffe JS. Underwater microscopy for in situ studies of benthic ecosystems. Nat Commun. 2016;7(1):12093. https://doi.org/10.1038/ncomms12093.

67. Nagai H, Takuwa K, Nakao M, Ito E, Masami M, Noda M, Nakajima T. Novel proteinaceous toxins from the box jellyfish (sea wasp) Carybdea rastoni. Biochem Biophys Res Commun. 2000;275:582-8.
68. Ng TJ, Teo MYM, Liew DS, Effiong PE, Hwang JS, Lim CSY, In LLA. Cytotoxic and apoptosis-inducing effects of wildtype and mutated Hydra actinoporinlike toxin 1 (HALT-1) on various cancer cell lines. PeerJ. 2019;7:e6639. https://doi.org/10.7717/peeri.6639.

69. Ostman C. A guideline to nematocyst nomenclature and classification, and some notes on the systematic value of nematocysts*. Scientia Marina, 2000; 64:31-46.

70. Peach MB, Hoegh-Guldberg O. Sweeper polyps of the coral Goniopora tenuidens (Scleractinia: Poritidae). Invertebr Biol. 1999;118(1):1-7. https://doi. org/10.2307/3226906.

71. Plachetzki DC, Fong CR, Oakley TH. Cnidocyte discharge is regulated by light and opsin-mediated phototransduction. BMC Biol. 2012;10(1):17. https://doi.org/10.1186/1741-7007-10-17.

72. Ponce D, Brinkman DL, Potriquet J, Mulvenna J. Tentacle transcriptome and venom proteome of the Pacific Sea Nettle, Chrysaora fuscescens (Cnidaria: Scyphozoa). Toxins. 2016;8(4):102

73. Prince RC, Gunson DE, Scarpa A. Sting like a bee! The ionophoric properties of melittin. Trends Biochem Sci. 1985;10:99.

74. Pritchard L, Dufton MJ. Evolutionary trace analysis of the Kunitz/BPTI family of proteins: functional divergence may have been based on conformational adjustment. J Mol Biol. 1999;285(4):1589-607.

75. Quinn RA, Vermeij MJA, Hartmann AC, d'Auriac IG, Benler S, Haas A, et al. Metabolomics of reef benthic interactions reveals a bioactive lipid involved in coral defence. Proc R Soc B Biol Sci. 2016;283(1829):20160469. https://doi. org/10.1098/rspb.2016.0469.

76. Rachamim T, Morgenstern D, Aharonovich D, Brekhman V, Lotan T, Sher D. The dynamically evolving nematocyst content of an anthozoan, a scyphozoan, and a hydrozoan. Mol Biol Evol. 2015;32. https://doi.org/10. 1093/molbev/msu335.

77. Reed $\sqcup$, Muench S. A simple method of estimating fifty per cent end point. Am J Hyg. 1938;27:493

78. Rigoni M, Caccin P, Gschmeissner S, Koster G, Postle AD, Rossetto O, Montecucco C. Equivalent effects of snake PLA2 neurotoxins and Lysophospholipid-fatty acid mixtures. Science. 2005;310(5754):1678-80. https://doi.org/10.1126/science.1120640.

79. Rohou A, Nield J, Ushkaryov YA. Insecticidal toxins from black widow spider venom. Toxicon. 2007:49(4):531-49. https://doi.org/10.1016/j.toxicon.2006.11.021.

80. Schmidt CA, Daly NL, Wilson DT. Coral venom toxins. Front Ecol Evol. 2019; 7(320). https://doi.org/10.3389/fevo.2019.00320.

81. Sebens KP, Miles JS. Sweeper tentacles in a gorgonian octocoral: morphological modifications for interference competition. Biol Bull. 1988; 175(3):378-87. https://doi.org/10.2307/1541729.

82. Seneca FO, Palumbi SR. The role of transcriptome resilience in resistance of corals to bleaching. Mol Ecol. 2015;24(7):1467-84. https://doi.org/10.1111/ mec.13125.

83. Sher D, Fishman Y, Melamed-Book N, Zhang M, Zlotkin E. Osmotically driven prey disintegration in the gastrovascular cavity of the green hydra by a pore-forming protein. FASEB J. 2008;22(1):207-21.

84. Sher D, Zlotkin E. A hydra with many heads: protein and polypeptide toxins from hydra and their biological roles. Toxicon. 2009;54(8):1148-61. https:// doi.org/10.1016/j.toxicon.2009.02.036

85. Soto C, Bergado G, Blanco R, Griñán T, Rodríguez H, Ros U, Álvarez C. Sticholysin II-mediated cytotoxicity involves the activation of regulated intracellular responses that anticipates cell death. Biochimie. 2018;148:18-35. https://doi.org/10.1016/j.biochi.2018.02.006.

86. Stabili L, Schirosi R, Parisi MG, Piraino S, Cammarata M. The mucus of Actinia equina (Anthozoa, Cnidaria): an unexplored resource for potential applicative purposes. Mar Drugs. 2015;13(8):5276-96.

87. Sunagar K, Columbus-Shenkar YY, Fridrich A, Gutkovich N, Aharoni R, Moran $Y$. Cell type-specific expression profiling unravels the development and evolution of stinging cells in sea anemone. BMC Biol. 2018;16(1):108. https:// doi.org/10.1186/s12915-018-0578-4

88. Tardent $P$. The cnidarian cnidocyte, a high-tech cellular weaponry. Bioessays. 1995:17(4):351-62.

89. Thornton DJ, Rousseau K, McGuckin MA. Structure and function of the polymeric mucins in airways mucus. Annu Rev Physiol. 2008;70(1):459-86. https://doi.org/10.1146/annurev.physiol.70.113006.100702.

90. Walker AA, Mayhew ML, Jin J, Herzig V, Undheim EAB, Sombke A, King GF. The assassin bug Pristhesancus plagipennis produces two distinct venoms in separate gland lumens. Nat Commun. 2018;9(1):755. https://doi.org/10. 1038/s41467-018-03091-5. 
91. Williams HF, Mellows BA, Mitchell R, Sfyri P, Layfield HJ, Salamah M, Vaiyapuri S. Mechanisms underpinning the permanent muscle damage induced by snake venom metalloprotease. PLoS Negl Trop Dis. 2019;13(1): e0007041. https://doi.org/10.1371/journal.pntd.0007041.

92. Williams P, Akande P, Catapane EJ, Carroll MA. Further studies on the sensory motor integration of gill lateral cilia in the bivalve mollusc Crassostrea virginica. FASEB J. 2013;27(1_supplement). https://doi.org/10 1096/fasebj.27.1_supplement.1120.1.

93. Williams RB. Acrorhagi, catch tentacles and sweeper tentacles: a synopsis of 'aggression' of actiniarian and scleractinian Cnidaria. Hydrobiologia. 1991; 216(1):539-45. https://doi.org/10.1007/bf00026511.

94. Ying H, Cooke I, Sprungala S, Wang W, Hayward DC, Tang Y, Miller DJ. Comparative genomics reveals the distinct evolutionary trajectories of the robust and complex coral lineages. Genome Biol. 2018;19(1):175. https://doi. org/10.1186/s13059-018-1552-8.

95. Zhang M, Fishman Y, Sher D, Zlotkin E. Hydralysin, a novel animal groupselective paralytic and cytolytic protein from a noncnidocystic origin in hydra. Biochemistry. 2003;42(30):8939-44.

96. Zlotkin E, Fraenkel G, Miranda F, Lissittzky S. The effect of scorpion venom on blowfly larvae; a new method for the evaluation of scorpion venom potency. Toxicon. 1971;9:1-8.

\section{Publisher's Note}

Springer Nature remains neutral with regard to jurisdictional claims in published maps and institutional affiliations.

Ready to submit your research? Choose BMC and benefit from:

- fast, convenient online submission

- thorough peer review by experienced researchers in your field

- rapid publication on acceptance

- support for research data, including large and complex data types

- gold Open Access which fosters wider collaboration and increased citations

- maximum visibility for your research: over $100 \mathrm{M}$ website views per year

At $\mathrm{BMC}$, research is always in progress.

Learn more biomedcentral.com/submissions 